\title{
Seletividade dos Herbicidas S-Metolachlor e Alachlor PaRa o FEIJÃo-CARIOCA ${ }^{1}$
}

\author{
Selectivity of Metolachlor and Alachlor for the "Carioca" Bean \\ LAMEGO, F.P. ${ }^{2}$, BASSO, C.J. ${ }^{3}$ VIDAL, R.A. ${ }^{4}$, TREZZI, M.M. ${ }^{5}$, SANTI, A.L. ${ }^{6}$, RUCHEL, Q. ${ }^{7}$, \\ KASPARY, T.E. ${ }^{8}$ e GALLON, M. ${ }^{9}$
}

\begin{abstract}
RESUMO - O feijoeiro é uma cultura de ciclo vegetativo curto, bastante sensivel à interferência de plantas daninhas. O objetivo deste trabalho foi avaliar a eficácia de herbicidas aplicados em pré-emergência no controle de Digitaria sanguinalis na cultura do feijão-carioca, bem como determinar a seletividade deles para a cultura. Os tratamentos avaliados foram: S-metolachlor (960, 1.440 e $\left.1.920 \mathrm{~g} \mathrm{ha}^{-1}\right)$, alachlor (1.440, 1.920 e $2.400 \mathrm{~g} \mathrm{ha}^{-1}$ ) e duas testemunhas sem aplicação de herbicidas (com e sem capinas). Avaliações visuais de controle para $D$. sanguinalis e fitotoxicidade para o feijão foram realizadas aos 20 e 40 dias após a emergência (DAE). Os herbicidas, em todas as doses avaliadas, foram eficientes no controle de $D$. sanguinalis. Aos 40 DAE, observou-se injúria no feijoeiro nas parcelas aspergidas com S-metolachlor nas maiores doses, porém sem efeito deletério na produtividade de grãos da cultura. O herbicida alachlor, embora eficiente no manejo de $D$. sanguinalis, causou fitotoxicidade ao feijão-carioca, reduzindo a produtividade da cultura em até $47 \%$.
\end{abstract}

Palavras-chave: alachlor, S-metolachlor, Digitaria sanguinalis, fitotoxicidade, componentes da produtividade.

\begin{abstract}
The common bean is a culture with a short vegetative cycle, highly susceptible to weed interference. The objective of this work was to evaluate the efficacy of herbicides applied in pre emergence for Digitaria sanguinalis control in "Carioca" bean crop, as well as to determine their selectivity to the crop. The treatments evaluated were: S-metolachlor (960; 1,440 and 1,920 $\mathrm{g} \mathrm{ha}$ (1), alachlor (1,440; 1,920 and 2,400 $\left.\mathrm{g} \mathrm{ha}^{-1}\right)$, and two untreated checks without herbicide application (with and without hoeing control). Visual evaluations of control for $\boldsymbol{D}$. sanguinalis and injury to the common bean plants were conducted at 20 and 40 days after emergence (DAE). At all the evaluated rates, the herbicides were efficient in $\boldsymbol{D}$. sanguinalis control. At $40 \mathrm{DAE}$, injury to the common bean was observed in the plots sprayed with S-metolachlor at the highest rates, but without deleterious effect on the crop grain yield. Despite being efficient in $\boldsymbol{D}$. sanguinalis management, alachlor caused phytotoxicity to the "Carioca" common bean, reducing crop yield up to $47 \%$.
\end{abstract}

Keywords: alachlor, S-metolachlor, Digitaria sanguinalis, phytotoxicity, yield components.

\section{INTRODUÇÃO}

O feijão (Phaseolus vulgaris) é um dos componentes básicos da dieta alimentar da população brasileira e importante fonte de proteína (FAO, 2007). É cultivado em diversos países; no Brasil, seu cultivo ocorre em três períodos do ano, denominados de safra de primeira ou das águas, safra de segunda ou das secas e safra de inverno. As duas primeiras são responsáveis por $90 \%$ da produção nacional e utilizam, respectivamente, 2,1 e 1,5 milhões

1 Recebido para publicação em 20.12.2010 e aprovado em 19.7.2011.

2 Professora, Dep. de Ciências Agronômicas e Ambientais, Universidade Federal de Santa Maria - UFSM/CESNORS, Linha Sete de Setembro s/n BR 386 Km 40, 98400-000 Frederico Westphalen-RS, <fabilamego@yahoo.com.br>; ${ }^{3}$ Professor, Dep. de Ciências Agronômicas e Ambientais, UFSM/CESNORS, <claudirbasso@gmail.com>; ${ }^{4}$ Professor, Dep. de Plantas de Lavoura, Universidade Federal do Rio Grande do Sul - UFRGS, <ribas.vidal@gmail.com>; ${ }^{5}$ Professor, Universidade Tecnológica Federal do Paraná - UTFPR, <trezzim@gmail.com>; ${ }^{6}$ Professor, Dep. de Ciências Agronômicas eAmbientais, UFSM/CESNORS, <santi_pratica@yahoo.com.br>; ${ }^{7}$ Graduanda do Curso de Agronomia, UFSM/CESNORS, <queli.ruchel@yahoo.com.br $>$; ${ }^{8}$ Graduando do Curso de Agronomia, UFSM/ CESNORS, <tiagokaspary@hotmail.com>; ${ }^{9}$ Graduando do Curso de Agronomia, UFSM/CESNORS, <mateusgallon@hotmail.com>. 
de hectares (IBGE, 2008). O consumo per capita de feijão é de $16,3 \mathrm{~kg}^{1} \mathrm{hab}^{1} \mathrm{ano}^{-1}$, sendo uma cultura de grande importância, com cultivo em grande parte do território nacional, nas mais variadas condições, sejam elas climáticas ou tecnológicas (Pereira et al., 2010).

Das culturas anuais cultivadas no Brasil, provavelmente o feijão é a que tem mais elevada perda percentual com a interferência de plantas daninhas. Por ser uma cultura de ciclo relativamente curto, o feijão é bastante sensivel à competição imposta pelas plantas infestantes, sobretudo nas fases iniciais de desenvolvimento. Trabalhos em que se avaliou a perda de grãos de feijão-carioca quando em competição com Brachiaria plantaginea indicaram que o período crítico de prevenção da interferência (PCPI), ou seja, a fase em que impreterivelmente deve-se adotar algum tipo de manejo das infestantes, evitando maior comprometimento da produtividade da cultura, situa-se entre 15 e 30 dias DAE (Passini et al., 2002). Em feijão-caupi, as produtividades de três cultivares foram reduzidas em até 90\% quando a convivência com as plantas daninhas ocorreu durante todo o ciclo; nesse caso, o período anterior à interferência pelas plantas daninhas (PAI) variou de 0 a 7 dias após a semeadura do feijão, justificando o controle essencial de plantas daninhas após esse periodo, ou seja, dentro do PCPI (Oliveira et al., 2010). Além disso, a permanência de plantas daninhas na lavoura prejudica a operação de colheita, pois elas servem como hospedeiras para pragas e, sobretudo, patógenos.

Milhã (Digitaria sanguinalis) é uma gramínea de ciclo anual, bastante competitiva com os cultivos agrícolas e que se reproduz por sementes (Kissman \& Groth, 1997). Essa espécie daninha está amplamente disseminada pelo Brasil, com maior ocorrência nas regiões Sul e Sudeste. As perdas de grãos são afetadas pela interação entre a densidade de plantas daninhas e o seu período de convivência com a cultura (Skora Neto, 2010). A densidade de 25 plantas $\mathrm{m}^{-2}$ de Brachiaria plantaginea reduziu a produtividade do feijoeiro em $70 \%$ quando as plantas emergiram oito dias antes da cultura (Passini et al., 2002).

O feijão pode ser cultivado em muitas propriedades de pequena área; em boa parte delas, o manejo de plantas daninhas acaba sendo realizado através de capinas manuais. Todavia, além do trabalho árduo, nem sempre a capina é realizada no momento oportuno, podendo comprometer a produtividade de grãos (Vidal et al., 2010). O uso criterioso de herbicidas pré-emergentes com efeito residual que garanta o estabelecimento da cultura no limpo é uma opção vantajosa, pois evita os efeitos negativos da competição inicial com as espécies competidoras. Alguns herbicidas são registrados para o controle de plantas daninhas em pré-emergência no feijoeiro, como trifluralina, S-metolachlor e pendimethalin (Andrei, 2005). No entanto, ainda são necessários maiores estudos quanto à seletividade de herbicidas existentes no mercado para cultivares de feijão do grupo Carioca.

Entre os critérios científicos para seleção da dose dos herbicidas, destacam-se critérios agronômicos e econômicos. Os primeiros referem-se à dose necessária para conferir eficácia no controle das espécies efetivamente presentes na área. A dose selecionada dependerá do estádio de desenvolvimento das infestantes e das condições ambientais, como características físicas e químicas do solo (Barros et al., 2005). Os critérios econômicos referem-se à dose para otimizar o retorno econômico na atividade (Dieleman et al., 1996).

Numa análise agronômica e econômica, comprovou-se que a dose necessária para otimizar o controle de infestantes na cultura do trigo era superior à necessária para otimizar o lucro do agricultor. Esse fenômeno foi denominado "paradoxo da dose" (Vidal \& Kalsing, 2009). Estudos conduzidos por Trezzi et al. (2010) demonstram haver redução no rendimento de grãos nas doses mais altas de herbicidas, provavelmente relacionada à toxicidade destes às plantas de feijão.

O objetivo deste trabalho foi investigar a seletividade de herbicidas aplicados em préemergência para a cultura de feijão-carioca, bem como a sua eficácia no controle de Digitaria sanguinalis.

\section{MATERIAL E MÉTODOS}

O experimento foi conduzido em Taquaruçu do Sul - RS, em solo caracterizado como Latossolo Vermelho alumino-férrico 
(Embrapa, 1999), com as seguintes características físicas e químicas: $\mathrm{pH}$ em água( $(1: 1)$ : 5,7; indice SMP: 6,2; argila: $300 \mathrm{~g} \mathrm{~kg}^{-1}$; matéria orgânica: $240 \mathrm{~g} \mathrm{~kg}^{-1}$; potássio, cálcio, magnésio e alumínio: $0,17,10,1,3,0$ e $0 \mathrm{cmol} \mathrm{dm}^{-3}$, respectivamente; e P-Mehlich, enxofre e Mn: 2,2 e 12,0 e $27 \mathrm{mg} \mathrm{dm}^{-3}$, respectivamente. Os tratamentos foram dispostos em delineamento experimental de blocos casualizados, com quatro repetições. Foram comparados os tratamentos: S-metolachlor, nas doses de 960, 1.440 e $1.920 \mathrm{~g} \mathrm{ha}^{-1}$; alachlor, nas doses de $1.440,1.920$ e $2.400 \mathrm{~g} \mathrm{ha}^{-1}$; e duas testemunhas, sendo uma capinada e outra sem capina.

Antes da instalação do experimento, durante o inverno, a área esteve cultivada com aveia-preta (Avena strigosa). Quinze dias antes da semeadura do feijão, a área foi dessecada com o herbicida glyphosate (900 g e.a ha-1), sendo repetida a dessecação na véspera do plantio. A semeadura do feijão, grupo Carioca, cultivar Juriti Branco, foi realizada com semeadora, no espaçamento de $0,45 \mathrm{~m}$ entre linhas, para atingir a densidade de 30 plantas $\mathrm{m}^{-2}$, no dia 5/11/2009. Na ocasião, o solo foi adubado aplicando-se $600 \mathrm{~kg} \mathrm{ha}^{-1} \mathrm{da}$ fórmula 9-33-12, correspondendo a 54, 198 e $72 \mathrm{~kg} \mathrm{ha}^{-1}$ de $\mathrm{N}, \mathrm{P}_{2} \mathrm{O}_{5}$ e $\mathrm{K}_{2} \mathrm{O}$, respectivamente. A adubação de cobertura foi realizada com $60 \mathrm{~kg} \mathrm{ha}^{-1}$ de ureia, quando as plantas atingiram o estádio V6. O controle das dicotiledôneas foi obtido com aplicação dos herbicidas bentazon + fomesafen $\left(600+125 \mathrm{~g} \mathrm{ha}^{-1}\right)$, acrescidos de 0,5\% v/v do óleo mineral Assist, realizada no dia 3/12/2009, incluindo as parcelas correspondentes às testemunhas (com e sem capinas). As parcelas foram compostas por seis linhas de $4,0 \mathrm{~m}$ de comprimento, espaçadas de $0,45 \mathrm{~m}$ entre si. A área útil foi composta pelas duas linhas centrais, descartando-se $0,50 \mathrm{~m}$ em cada uma das extremidades.

Os tratamentos com herbicidas foram aplicados no dia seguinte ao plantio da cultura, em pré-emergência, com pulverizador costal de precisão, pressurizado com $\mathrm{CO}_{2}$, com barra de quatro bicos espaçados de $50 \mathrm{~cm}$, contendo pontas XR 8002, mantendo-se pressão constante de $200 \mathrm{kPa}$. A velocidade de deslocamento foi de $1 \mathrm{~m} \mathrm{~s}^{1}$, com volume de calda de $200 \mathrm{~L} \mathrm{ha}^{-1}$.
Realizaram-se avaliações visuais de controle de $D$. sanguinalis e de injúria para a cultura do feijão aos 20 e 40 DAE, através de notas atribuídas por dois avaliadores. A escala visual utilizada consistiu de nota zero para ausência de controle e/ou ausência de sintoma de dano à cultura e 100 para controle total das infestantes ou morte das plantas de feijão. A colheita manual de todas as plantas na área útil foi realizada no dia $3 / 2 / 2010$. Os componentes da produtividade de grãos $\left(\mathrm{n}^{\circ} \mathrm{de}\right.$ legumes por planta, $\mathrm{n}^{\circ}$ de grãos por legume e peso de 100 grãos) foram avaliados em dez plantas amostradas aleatoriamente em cada unidade experimental. A produtividade de grãos foi obtida a partir da massa de grãos colhidos na área útil da parcela, com umidade corrigida para $13 \%$, e os dados, convertidos para $\mathrm{kg} \mathrm{ha}{ }^{-1}$.

Os dados obtidos no experimento foram submetidos à análise de variância, por meio do teste $F$; havendo significância, as médias dos tratamentos foram comparadas aplicandose o teste de Duncan, adotando-se o nivel de $5 \%$ de probabilidade. A densidade de plantas de $D$. sanguinalis foi determinada aos 20 e 40 dias após a emergência do feijão (DAE) por meio da contagem do número de plantas, realizada em um quadrado de $0,25 \mathrm{~m}^{2}$, posicionado ao acaso, em cada unidade experimental. Posteriormente, determinou-se a relação entre a densidade da planta daninha e a perda da produtividade de grãos pela cultura do feijão, de acordo com o procedimento descrito por Vidal et al. (2004), utilizando-se o modelo de regressão não linear derivado da hipérbole retangular, dado pela equação:

$$
P=A^{*} d /\left(D_{50}+d\right)
$$

em que: $P=$ perda $(\%)$ de produtividade; $d=$ densidade (plantas $\mathrm{m}^{-2}$ ) de $D$. sanguinalis aos $20 \mathrm{DAE} ; A=$ assintota máxima, ou seja, é a perda $(\%)$ de produtividade quando a densidade de $D$. sanguinalis tende ao infinito; e $D_{50}=$ indica a densidade em que a perda de rendimento atinge $50 \%$ da máxima. A razão $A / D_{50}=\mathrm{i}$ indica a perda $(\%)$ de produtividade quando a população de $D$. sanguinalis se aproxima de zero (Vidal et al., 2010). O ajuste do modelo aos dados foi realizado usando-se o programa Sigma Plot versão 10.0.

Planta Daninha, Viçosa-MG, v. 29, n. 4, p. 877-883, 2011 


\section{RESULTADOS E DISCUSSÃO}

Os herbicidas avaliados promoveram, de maneira geral, controle eficiente de $D$. sanguinalis na cultura do feijão (Tabela 1 ). $\mathrm{Na}$ primeira avaliação, realizada aos $20 \mathrm{DAE}$, observou-se que, na média, os tratamentos envolvendo os herbicidas S-metolachlor e alachlor não diferiram estatisticamente ( $p>0,05)$ quanto ao controle da planta daninha. Nessa época, S-metolachlor apresentou controle médio de $92 \%$ na maior dose testada (1.920 $\left.\mathrm{g} \mathrm{ha}^{-1}\right)$, enquanto alachlor proporcionou $93 \%$ de controle médio de $D$. sanguinalis na dose de $1.440 \mathrm{~g} \mathrm{ha}^{-1}$. Já aos $40 \mathrm{DAE}$, para S-metolachlor, com exceção da menor dose avaliada (960 $\left.\mathrm{g} \mathrm{ha}^{-1}\right)$, que apresentou controle de $89 \%$, as doses de 1.440 e $1.920 \mathrm{~g} \mathrm{ha}^{-1}$ foram satisfatórias, com controles médios para $D$. sanguinalis de 94 e $96 \%$, respectivamente. Para o herbicida alachlor, nesta mesma época, não houve diferença significativa entre as doses avaliadas para o controle da infestante $(p>0,05)$. Na média, a porcentagem de controle para este herbicida foi equivalente a $90 \%$, sendo, portanto, inferior às maiores doses de S-metolachlor avaliadas (Tabela 1).

Resultados semelhantes foram observados por Khan \& Hassan (2003), avaliando a eficiência de controle de S-metolachlor sobre diferentes espécies infestantes, incluindo $D$. sanguinalis, nas culturas de quiabo, canade-açúcar, milho e batata. Na cultura do algodão, herbicidas aplicados em pré-emergência, como S-metolachlor, foram eficientes no controle inicial de plantas daninhas, embora não tenham sido eficientes para permitir a colheita da cultura sem a interferência das infestantes (Freitas et al., 2006). Uma vez que o periodo em que as plantas daninhas causam maiores danos ao feijão compreende os primeiros $30 \mathrm{DAE}$, a eficiência de controle observada pelos herbicidas testados neste trabalho garante o crescimento da cultura praticamente no limpo, ou seja, sem a interferência de plantas competidoras.

A injúria na cultura do feijão do grupo Carioca, quando avaliada aos $20 \mathrm{DAE}$, foi elevada quando se aplicou o herbicida alachlor, com niveis de intoxicação acima de 58\% (Tabela 1), apresentando redução de crescimento das plantas de feijão quando comparada àquelas sem aplicação do herbicida. Já nos tratamentos que envolveram aplicação do herbicida S-metolachlor, observou-se apenas leve injúria, inferior a $5 \%$, na maior dose do herbicida (1.920 $\left.\mathrm{g} \mathrm{ha}^{-1}\right)$.

Aos 40 DAE, para S-metolachlor nas maiores doses ( 1.440 e $1.920 \mathrm{~g} \mathrm{ha}^{-1}$ ), também foi constatado efeito fitotóxico pelo herbicida, porém com niveis de intoxicação inferiores a $15 \%$ (Tabela 1). Para o herbicida alachlor, em todas as doses testadas, as plantas de feijão ainda apresentavam sintomas de dano aos 40 DAE, embora inferiores aos observados aos 20 DAE (Tabela 1). Os sintomas observados foram caracterizados pela redução do crescimento das plantas de feijão. Efeitos semelhantes foram observados na cultura do algodão

Tabela 1 - Controle de Digitaria sanguinalis e injúria para a cultura do feijão, grupo Carioca. Taquaruçu do Sul-RS, 2009/10

\begin{tabular}{|l|c|c|c|c|c|}
\hline \multicolumn{1}{|c|}{ Tratamento } & $\begin{array}{c}\text { Dose } \\
\left(\mathrm{g} \mathrm{ha}^{-1}\right)\end{array}$ & Controle 20 DAE & Controle 40 DAE & Injúria 20 DAE & Injúria 40 DAE \\
\hline Testemunha capinada & --- & $100 \mathrm{~A}^{3 /}$ & $100 \mathrm{~A}$ & $0 \mathrm{~B}$ & $0 \mathrm{C}$ \\
\hline Testemunha infestada & --- & $0 \mathrm{C}$ & $0 \mathrm{C}$ & $0 \mathrm{~B}$ & $0 \mathrm{C}$ \\
\hline S-metolachlor & 960 & $91 \mathrm{AB}$ & $89 \mathrm{~B}$ & $0 \mathrm{~B}$ & $0 \mathrm{C}$ \\
\hline S-metolachlor & 1.440 & $90 \mathrm{~B}$ & $94 \mathrm{AB}$ & $0 \mathrm{~B}$ & $10 \mathrm{BC}$ \\
\hline S-metolachlor & 1.920 & $92 \mathrm{AB}$ & $96 \mathrm{AB}$ & $5 \mathrm{~B}$ & $14 \mathrm{BC}$ \\
\hline Alachlor & 1.440 & $93 \mathrm{AB}$ & $91 \mathrm{~B}$ & $58 \mathrm{~A}$ & $20 \mathrm{AB}$ \\
\hline Alachlor & 1.920 & $91 \mathrm{AB}$ & $91 \mathrm{~B}$ & $65 \mathrm{~A}$ & $30 \mathrm{~A}$ \\
\hline Alachlor & 2.400 & $88 \mathrm{~B}$ & $90 \mathrm{~B}$ & $58 \mathrm{~A}$ & $26 \mathrm{AB}$ \\
\hline \multicolumn{1}{c}{$\mathrm{CV}(\%)^{\underline{1} /}$} & & 7,44 & 5,45 & 58,8 & 37,2 \\
\hline
\end{tabular}

${ }^{1 /}$ Coeficiente de variação. ${ }^{2 /}$ Dias após a emergência. ${ }^{3 /}$ Médias seguidas de letras idênticas, nas colunas, não diferem entre si pelo teste de Duncan a $5 \%$ de probabilidade. 
com o herbicida alachlor (Guimarães et al., 2007).

Cloroacetamidas são herbicidas residuais utilizados para controle de plantas daninhas em pré-emergência nas culturas de soja, mi1ho, café, feijão e cana-de-açúcar. O mecanismo primário de ação desses herbicidas está na inibição da síntese de ácidos graxos de cadeias longas (Silva et al., 2007). Nesse grupo químico destacam-se os herbicidas acetochlor, alachlor e S-metolachlor; suas atividades são influenciadas pelos teores de argila e matéria orgânica, pela umidade do solo e pela cobertura do solo com palha (Banks \& Robinson, 1986). Na cultura do algodão, S-metolachlor mostrou-se eficiente no manejo de diferentes espécies daninhas quando associado ao herbicida trifloxysulfuron-sodium (Freitas et al., 2006). Dependendo da cultura, pode haver baixa seletividade por esses herbicidas, muitas vezes tornando-se necessário o uso de protetores com a finalidade de viabilizar o uso desses compostos no controle das plantas daninhas.

Aos cinco dias após a semeadura do feijão e a aplicação dos herbicidas em pré-emergência, ocorreu precipitação pluvial acentuada, o que atrasou a emergência da cultura e pode ter favorecido a lixiviação dos herbicidas, aumentando seu efeito de fitotoxicidade. De maneira geral, quanto mais rápida for a emergência da plântula da cultura e o crescimento de suas raízes, menos tempo esses órgãos ficarão em contato com o herbicida no solo e menor deve ser sua absorção. Essa assertiva é corroborada pelo maior dano observado após aplicação de alachlor em condições desfavoráveis à germinação das culturas de batata (Belote \& Monaco, 1977) e feijão (Putnam \& Rice Junior, 1979).

O herbicida S-metolachlor não alterou a produtividade e o número de legumes por planta do feijão-carioca, independentemente da dose aplicada, apresentando resultados semelhantes aos da testemunha capinada; já alachlor reduziu a produtividade da cultura em todas as doses estudadas, embora o número de legumes por planta tenha sido alterado apenas nas duas maiores doses (Tabela 2). A produtividade dos tratamentos submetidos à aplicação do alachlor foi inferior à do tratamento mantido sob infestação de $D$. sanguinalis, o que evidencia o efeito da intoxicação da cultura pelo herbicida, indicando que este herbicida não é seletivo para o cultivar do grupo Carioca avaliado, assim como observado para outras culturas, como sorgo e milho (Ellis et al., 1980; Repasi et al., 1996).

$\mathrm{Na}$ ausência de efeito deletério causado pelos herbicidas, observou-se que o impacto das densidades de $D$. sanguinalis sobre a produtividade do feijão-carioca é menor do que na condição com injúria da cultura (Figura 1). Desse modo, uma planta $\mathrm{m}^{-2}$ de $D$. sanguinalis reduz a produtividade do feijão em $0,62 \%$ quando na ausência de dano do herbicida residual na cultura, enquanto na presença

Tabela 2 - Componentes da produtividade e produtividade de grãos para a cultura do feijão, grupo carioca. Taquaruçú do Sul-RS, 2009/10

\begin{tabular}{|l|c|c|c|c|c|}
\hline \multicolumn{1}{|c|}{ Tratamento } & $\begin{array}{c}\text { Dose } \\
\left(\mathrm{g} \mathrm{ha}^{-1}\right)\end{array}$ & $\begin{array}{c}\text { Legumes por } \\
\text { planta }\left(\mathrm{n}^{\underline{0}}\right)\end{array}$ & $\begin{array}{c}\text { Grãos por legume } \\
\left(\mathrm{n}^{\mathrm{o}}\right)\end{array}$ & $\begin{array}{c}\text { Peso de } 100 \text { grãos } \\
(\mathrm{g})\end{array}$ & $\begin{array}{c}\text { Produtividade de } \\
\text { grãos }\left(\mathrm{kg} \text { ha }^{-1}\right)\end{array}$ \\
\hline Testemunha capinada & --- & $13,1 \mathrm{~A}^{\underline{2}}$ & $3,4 \mathrm{~A}$ & $27,6 \mathrm{~A}$ & $2.379 \mathrm{~A}$ \\
\hline Testemunha infestada & --- & $12,2 \mathrm{AB}$ & $3,8 \mathrm{~A}$ & $27,6 \mathrm{~A}$ & $1.729 \mathrm{ABCD}$ \\
\hline S-metolachlor & 960 & $11,1 \mathrm{ABC}$ & $3,7 \mathrm{~A}$ & $27,4 \mathrm{~A}$ & $2.097 \mathrm{AB}$ \\
\hline S-metolachlor & 1.440 & $12,2 \mathrm{AB}$ & $3,8 \mathrm{~A}$ & $28,3 \mathrm{~A}$ & $1.944 \mathrm{ABC}$ \\
\hline S-metolachlor & 1.920 & $11,4 \mathrm{ABC}$ & $3,5 \mathrm{~A}$ & $28,7 \mathrm{~A}$ & $2.172 \mathrm{AB}$ \\
\hline Alachlor & 1.440 & $10,1 \mathrm{ABC}$ & $3,6 \mathrm{~A}$ & $28,9 \mathrm{~A}$ & $1.635 \mathrm{BCD}$ \\
\hline Alachlor & 1.920 & $8,5 \mathrm{C}$ & $3,4 \mathrm{~A}$ & $28,7 \mathrm{~A}$ & $1.339 \mathrm{CD}$ \\
\hline Alachlor & 2.400 & $9,7 \mathrm{BC}$ & $3,3 \mathrm{~A}$ & $27,6 \mathrm{~A}$ & $1.256 \mathrm{D}$ \\
\hline \multicolumn{1}{|c|}{$\mathrm{CV}(\%)^{\underline{1 /}}$} & & 16,8 & 8,0 & 3,4 & 22,8 \\
\hline
\end{tabular}

${ }^{1 /}$ Coeficiente de variação. ${ }^{2 /}$ Médias seguidas de letras idênticas, nas colunas, não diferem entre si pelo teste de Duncan a 5\% de probabilidade 
desse efeito a redução é de 0,99\% (Tabela 3). A planta cultivada que sofre fitotoxicidade pela ação do herbicida é menos competitiva, tornando-se portanto, mais sensível à pressão imposta pela planta daninha infestante. Isto é comprovado pelos valores observados para o parâmetro $i$ (Tabela 3), na condição de ausência e presença do herbicida (sem e com fitotoxicidade à cultura).

Trezzi et al. (2010) também observaram, na cultura do feijão, o efeito das doses dos herbicidas bentazon+imazamox sobre a produtividade de grãos. Entre as doses de 0 e $0,7 \mathrm{~L} \mathrm{ha}^{-1}$, houve incremento da produtividade de 1.875 para $2.150 \mathrm{~kg} \mathrm{ha}^{-1}$, ou seja, um incremento de $13 \%$ em relação à testemunha. A

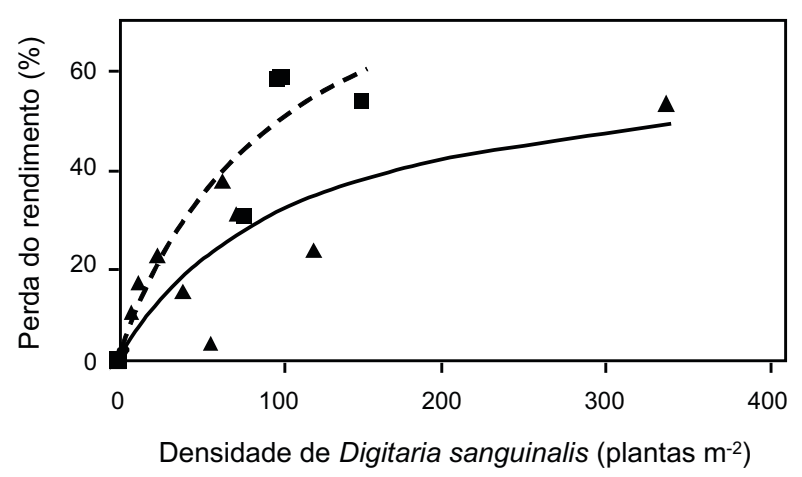

Figura 1 - Perda da produtividade de grãos do feijão (\%), grupo Carioca, cv. Juriti Branco, em função da densidade de Digitaria sanguinalis, em condição $\operatorname{sem}(\boldsymbol{\Delta})$ e $\operatorname{com}(\boldsymbol{\square})$ fitotoxicidade de herbicidas residuais aos 40 dias após a emergência (DAE). Taquaruçu do Sul-RS, 2009/10.

Tabela 3 - Parâmetros da equação ${ }^{1 /}$ de correlação entre a densidade de Digitaria sanguinalis (plantas $\mathrm{m}^{-2}$ ) aos 40 dias após a emergência e a queda do rendimento de feijão (\%). Taquaruçu do Sul-RS, 2009/10

\begin{tabular}{|l|c|c|c|c|}
\hline \multirow{2}{*}{$\begin{array}{c}\text { Condição } \\
\text { experimental }\end{array}$} & \multicolumn{3}{|c|}{ Parâmetros da equação } & \multirow{2}{*}{$\mathrm{R}^{2}$ ajustado } \\
\cline { 2 - 4 } & $\mathrm{A}$ & $\mathrm{D} 50$ & $\mathrm{i}$ & \\
\hline Sem alachlor & 62,6 & 100,9 & 0,62 & $0,55^{* * 2 /}$ \\
\hline Com alachlor & 99,6 & 99,7 & 0,99 & $0,80^{*}$ \\
\hline
\end{tabular}

${ }_{1}^{1 /} \mathrm{QR}=\mathrm{A} * \mathrm{~d} / \mathrm{D}_{50}+\mathrm{d}$, em que $\mathrm{QR}=$ queda do rendimento de grãos do feijoeiro; $A=$ assíntota superior ou queda máxima; $d=$ densidade $d a$ infestante; $\mathrm{D}_{50}=$ densidade que confere $50 \%$ de queda do rendimento da cultura. O parâmetro i (efeito estimado de cada infestante na queda do rendimento quando a densidade tende a zero) é obtido da razão entre $\mathrm{A}$ e $\mathrm{D}_{50}$, conforme Vidal \& Portugal (2010). 르 Significância pelo teste $\mathrm{t}$, em que ${ }^{*} \mathrm{P}<0,05$ e ${ }^{* *} \mathrm{P}<0,01$. partir da dose de $0,7 \mathrm{~L} \mathrm{ha}^{-1}$ houve redução da produtividade de grãos da cultura. $\mathrm{O}$ "paradoxo da dose" é uma teoria proposta recentemente que preconiza que a dose necessária para otimizar o controle de infestantes é superior àquela necessária para otimizar o lucro do agricultor (Vidal \& Kalsing, 2009). A redução da produtividade de grãos nas doses mais altas provavelmente está relacionada à toxicidade dos herbicidas às plantas de feijão. Os resultados dessa teoria indicam um antagonismo de objetivos/resultados por que passa o agricultor e possibilitam entender a atitude deste ao reduzir as doses dos herbicidas utilizados. No entanto, uma das possiveis consequências dessa estratégia é a seleção de biótipos de plantas daninhas resistentes aos herbicidas (Neve $\&$ Powles, 2005). No presente trabalho, esse paradoxo pode ser explicado, em parte, pela fitotoxicidade dos herbicidas utilizados.

A opção pelo uso de herbicidas pré-emergentes em sistema de semeadura convencional deve ser feita de forma criteriosa, considerando aspectos como textura do solo, teor de matéria orgânica e precipitações pluviais ocorrentes muito próximas à aplicação dos produtos. Esses fatores podem influenciar o resultado final, afetando a eficiência de controle das espécies daninhas e podendo também causar maior ou menor fitotoxicidade pelas plantas cultivadas. Assim, S-metolachlor pode ser utilizado de forma eficiente em préemergência no manejo de Digitaria sanguinalis na cultura do feijão-carioca, cultivar Jutiti Branco, sem comprometer a produtividade da cultura. O herbicida alachlor causa fitotoxicidade elevada ao feijão-carioca, comprometendo o rendimento final da cultura.

\section{AGRADECIMENTOS}

À família Turchetto, pela área cedida para condução do experimento e pelo auxílio na sua instalação e colheita; e aos alunos do curso de Agronomia da UFSM/Cesnors, pelo auxilio no processamento dos dados de colheita.

\section{LITERATURA CITADA}

ANDREI, E. Compêndio de defensivos agrícolas. 7.ed. São Paulo: Andrei, 2005. 1141 p. 
BANKS, A. P.; ROBINSON, E. L. Soil reception and activity of acetochlor, alachlor, and metolachlor as affected by wheat (Triticum aestivum) straw and irrigation. Weed Sci., v. 34, n. 4, p. 607-611, 1986.

BARROS, J. F. C.; BASCH, G.; CARVALHO, M. Effect of reduced doses of a post-emergence graminicide mixture to control Lolium rigidum $\mathrm{G}$. in winter wheat under direct drilling in Mediterranean environment. Crop Protec., v. 24, n. 6, p. $880-887,2005$.

BELOTE, J, N.; MONACO, T. J. Factors involved in alachlor injury to the potato (Solanum tuberosum). Weed Sci., v. 25, n. 6, p. 482-486, 1977.

DIELEMAN, A. et al. Decision rules for postemergence control of pigweed (Amaranthus spp.) in soybean (Glycine max). Weed Sci., v. 44, n. 1, p. 126-132, 1996.

ELLIS, J. F. et al. Effectiveness of a new safener for protecting sorghum (Sorghum bicolor) from metolachlor injury. Weed Sci., v. 28, n. 1, p. 1-5, 1980.

\section{EMPRESA BRASILEIRA DE PESQUISA}

AGROPECUÁRIA - EMBRAPA. Sistema brasileiro de classificação de solos. Brasília: 1999. 412 p.

FAO. Faostat. Disponível em: <http://faostat.fao.org/site/ 567/DesktopDefault.aspx?PageID=567> . Acesso em: 10 maio 2007.

FREITAS, R. S. et al. Manejo de plantas daninhas na cultura do algodoeiro com S-metolachlor e trifloxysulfuron-sodium em sistema de plantio convencional. Planta Daninha, v. 24, n. 2, p. 311-318, 2006.

GUIMARÃES, S. C.; HRYCYK, M. F.; MENDONÇA, E. A F. Efeito de fatores ambientais sobre a seletividade do alachlor ao algodoeiro. Planta Daninha, v. 25, n. 4, p. 813-821, 2007.

\section{INSTITUTO BRASILEIRO DE GEOGRAFIA E} ESTATÍSTICA - IBGE. Levantamento sistemático da produção agrícola. 2008. Disponível em: $<\mathrm{http}: / /$ www.ibge.gov.br/home/presidencia/noticias/noticia visualiza.php?id_noticia $=1068 \& i d \_p a g i n a=1>$. Acesso em: 2 ago. de 2010 .

KHAN, M.; HASSAN, W. Effect of S-metolachlor (Dual Gold 960 EC) on weed control and yields in different crops. Sarhad J. Agric., v. 19, n. 3, p. 333-339, 2003.

KISSMAN, K. G.; GROTH, D. Plantas infestantes e nocivas. 2.ed. São Paulo: BASF, 1997. p. 516-519.

NEVE, P.; POWLES, S. Recurrent selection with reduced herbicide rates results in the rapid evolution of herbicide resistance in Lolium rigidum. Theoret. Appl. Genetics, v. 110, n. 6, p. $1154-1166,2005$.
OLIVEIRA, O. M. S. et al. Período de convivência das plantas daninhas com cultivares de feijão-caupi em várzea no Amazonas. Planta Daninha, v. 28, n. 3, p. 523-530, 2010.

PASSINI, T.; CHRISTOFFOLETI, P. J.; DOURADO NETO, D. Modelos empíricos de predição de perdas de rendimento da cultura de feijão em convivência com Brachiaria plantaginea. Planta Daninha, v. 20, n. 2, p. 181-187, 2002.

PEREIRA, H. S. et al. Indicação de cultivares de feijoeirocomum baseada na avaliação conjunta de diferentes épocas de semeadura. Pesq. Agropec. Bras., v. 45, n. 6, p. 571-578, 2010

PUTNAM, A. R.; RICE JUNIOR, R. P. Environmental and edaphic influences on the selectivity of alachlor on snap beans (Phaseolus vulgaris). Weed Sci., v. 27, n. 5, p. 570-574, 1979.

REPASI, J. et al. N-1-aryl-N2-dichoroacetyl glycine and alanineamides as selective safeners for corn against chloroacetanilide herbicides. J. Environ. Sci. Health, v. 31, n. 3, p. 567-571, 1996.

SILVA, A. A.; FERREIRA, F. A.; FERREIRA, L. R Herbicidas: classificação e mecanismo de ação. In: SLVA,A. A.; SILVA, J. F. (Ed.). Tópicos em manejo de plantas daninhas. Viçosa-MG: Universidade Federal de Viçosa, 2007. p. $83-148$.

SKORA NETO, F.; CAMPOS, A. C.; HORSZYN, D. Interação entre densidade e período de convivência de plantas daninhas no feijoeiro (Phaseolus vulgaris). In: CONGRESSO BRASILEIRO DA CIÊNCIA DAS PLANTAS DANINHAS, 27., 2010, Ribeirão Preto. Anais... Ribeirão Preto: SBCPD, 2010. p. $775-779$.

TREZZI, M. M. et al. Paradoxo da dose de herbicidas: comprovação da teoria na cultura do feijão. In: CONGRESSO BRASILEIRO DA CIÊNCIA DAS PLANTAS DANINHAS, 27., 2010, Ribeirão Preto. Anais... Ribeirão Preto: SBCPD, 2010. p. $1635-1639$

VIDAL, R. A. et al. Nível de dano econômico de Brachiaria plantaginea na cultura de milho irrigado. Planta Daninha, v. 22, n. 1, p. 63-69, 2004.

VIDAL, R. A.; KALSING, A. Métodos para determinar a dose ótima de herbicidas na cultura do trigo. In: CONGRESSO DA SEMH/XIX CONGRESSO DA ALAM/II CONGRESSO DA IBCM, 12., 2009, Lisboa. Anais... Lisboa: Instituto Superior de Agricultura, 2009.

VIDAL. R. A. et al. Nível crítico de dano (NCD) de infestantes na cultura do feijão. In: VIDAL, R. A.; PORTUGAL, J.; SKORA NETO, F. Nível crítico de dano de infestantes em culturas anuais. Porto Alegre: EVANGRAF, 2010. p. 32-38. 